\title{
Tecnologías y lenguas en diálogo
}

si me hiere un rayo

Buenos Aires, 2005

\section{Silvia Calosso •}

Universidad Nacional del Litoral

El objeto que uno tiene en la mano cuando conoce este "texto" es una lata, una latita parecida a las de alimentos "en lata", con el diámetro de un disco compacto y con la posibilidad de destapar sin abrelatas. El título y autor de la obra están impresos en una etiqueta que contornea la lata en su pared vertical, de agradable diseño gráfico, que sustituye, dada la diferencia de formato, al habitual "arte de tapa" del libro tradicional. Adentro hay efectivamente un CD apoyado en espuma de nylon más un minúsculo volumen de poesías de ochenta y dos páginas.

Me parece importante consignar en primer lugar algunos datos sobre los editores de este volumen. Voy a salir y si me hiere un rayo es una editorial independiente "dedicada al registro de voces y textos de poetas contemporáneos latinoamericanos", tanto de autores inéditos como consagrados, que comenzó su actividad en marzo de 2004.

El catálogo, formado por discos en formato CDrom y audio, se estructura en dos colecciones: "Poesía joven latinoamericana", integrada por antologías por países y libros de autor y "Bonsái", colección que agrupa a poetas contemporáneos de reconocida trayectoria.

Según los integrantes del grupo editor, la idea de formar una editorial de estas características surgió por necesidad de crear un medio que permitiera el diálogo entre diferentes disciplinas y discursos que impactan sobre la producción poética actual (arte digital, música, cine, video, plástica, performance), y fundamentalmente, para documentar las voces de poetas latinoamericanos a fin de conformar un registro de los poetas de nuestro tiempo.

A partir del año 2006, la editorial ha lanzado, además, una nueva colección en el formato de libro tradicional. Un aspecto fundamental de este proyecto, dicen los editores, es la creación de un circuito independiente de difusión y distribución de publicaciones de poesía, una red que contenga tanto a los poetas de nuestro país como a los de todos los países de Latinoamérica.

Consigno estas informaciones dadas las insólitas características de este texto, en el que confluyen, como quieren sus editores, el formato digital/electrónico registrado en el disco, con el formato impreso tradicional, o sea el libro. Una de las

- Profesora en Letras para la Enseñanza Media y Superior. Docente Titular Ordinaria en las Carreras de Letras y Filosofía de la UNL, en Literaturas Griega y Latina, Gramática del Español y Lengua Griega Clásica. Vicedirectora del Centro de Estudios Comparados de la FHUC (UNL). Autora de libros y artículos de su especialidad. 
posibilidades de lectura es elegir entre escuchar la poesía desde el CD, en la voz de su autora, o leer la poesía en el libro. La otra es escuchar y leer simultáneamente, estableciendo un diálogo entre ambos formatos.

Pero el texto propone otros diálogos. La autora ha compuesto los poemas en español (que es su lengua-madre) y en inglés, lo cual nos propone un ejercicio teórico sobre el tema de la traducción, por ejemplo, qué mecanismos se juegan cuando un poeta traduce a otro idioma su propia poesía, y cuando la "lengua de llegada" no es la propia, sino una adquirida en algún momento de la vida, sea cual fuere. La misma pregunta nos propuso la obra El largo, largo viaje (2003), del escritor santafesino Ricardo Ahumada, recientemente fallecido, compuesta por poemas en español y alemán (esta última versión compuesta, como en el caso de Silvestri, por el mismo autor).

El otro diálogo que plantea este volumen es el de los textos poéticos de la autora con los de la antigüedad clásica, a los cuales explícitamente refieren. Un párrafo impreso en la "portada" de la lata (o sea su "etiqueta") dice: “...es un libro de poesía en formato CDrom y audio que reescribe las tragedias del sitio de Troya de Ilíada y Odisea, entre otros textos clásicos". Se habla aquí de reescritura, pero no se sabe, hasta leer atentamente, cuáles son los ecos que las obras clásicas generan en la autora. O bien sus poemas se producen a partir de los temas, los relatos, los argumentos, es decir, los contenidos (y a eso se refiere posiblemente el impreso de la portada cuando menciona "las tragedias" ${ }^{\text {) }}$, o bien, en su traspaso al español y al inglés esos textos, de alguna manera, son reescritos refiriendo a las formas poéticas de los griegos.

Quince son los poemas de este volumen en español, otros quince en inglés (¿cuál es el "testo a fronte"?). Efectivamente, nos encontramos allí con la voz de los protagonistas del mito y de las antiguas epopeyas. Hay una selección pareja de personajes femeninos y masculinos: siete son mujeres (incluso la infortunada reina fenicia Dido ha motivado un poema de Leonor Silvestri), y otros tantos varones. Ciertos anclajes en las experiencias presentes (Las Madres) sorprenden al lector: allí cuidadosamente la autora aclara quiénes son "las Madres" en el contexto de la historia reciente argentina. Lo más frecuente en la poesía de Leonor Silvestri es asumir la voz de sus "personajes" mitológicos o legendarios en la primera persona, en delicado tono intimista, que a veces dialoga con "el otro" (amante, esposo, enemigo), que ha motivado el conflicto. En ocasiones (Ayax, o Alexandros por ejemplo), esa voz no es la del personaje que da el título, sino la de un deuteragonista que le reclama, reprocha o lo ataca. Y el lector avisado repone el contexto del relato, en muchos casos extremadamente conocidos, como la Odisea.

La linealidad y economía sintáctica de los versos hacen que su versión al inglés tenga similares características. El texto fluye tranquilo, sencillo, con una laxitud que sin embargo da cuenta intensamente de los horrores de una guerra, de la dolorosa soledad de la viudez o del amor engañado, de la inconmensurable tristeza de las madres huérfanas de sus hijos.

El grupo editor y la autora se han dado un gusto con esta latita de versos. Ojalá transmitan ese placer a sus lectores/escuchas. 


\section{Notas}

${ }^{1}$ En el léxico cotidiano, usamos "tragedia" para referirnos a cualquier relato que contenga peripecias graves y final de muerte. Suponemos que ése es el sentido que la palabra tiene dentro de esta formulación, en la que se produce cierta ambigüedad, ya que en el contexto de la literatura griega clásica, el término tragedia describe un género poético tres siglos posterior a Iliada y Odisea. 